\title{
REKAYASA PEMBUATAN MESIN STRIP BAMBU
}

\section{Engineering the Construction of Stripper Machines In Bamboo Production}

\author{
Anhar Firdaus, dan Miyono \\ Balai Riset dan Standardisasi Industri \\ Jl. P. Batur Barat No.2. Telp./Fax. 0511-4772461/0511-4772115 Banjarbaru \\ E-mail : baristand.banjarbaru@gmail.com \\ Diterima, 10 September 2013, disetujui 20 Nopember 2013
}

\begin{abstract}
ABSTRAK
Bambu adalah salah satu hasil hutan non kayu yang dapat diberdayakan untuk berbagai keperluan. Salah satu pemanfaatan bambu sebagai bahan bangunan, yaitu dalam hal bentuk dan strip. Namun dengan semakin majunya teknologi perekatan maka bambu dapat dijadikan sebagai bahan baku substitusi inti (core) kayu lapis berupa strip. Tujuan penelitian ini adalah merekayasa mesin strip bambu untuk menghasilkan bilahbilah/strip-strip bambu dengan ukuran tebal seragam yang dapat diatur sesuai keinginan. Sebelum bambu ditipiskan menggunakan mesin strip (mesin penipis), batang bambu dipotong-potong terlebih dahulu sesuai dengan ukuran yang diinginkan. Bilah bambu yang telah simetris tersebut dimasukkan ke dalam mesin penipis melalui ujung pembawa bambu dari besi bentuk $U$ yang menuju roll penjepit. Pada ujung roll, tedapat mata pisau baja yang berfungsi untuk membelah dan menipiskan bilah bambu. Rendemen rata-rata hasil pembelahan 1 (satu) batang bambu berukuran tebal $8 \mathrm{~mm}$, lebar $1,5 \mathrm{~cm}$ dan panjang $30 \mathrm{~cm}$ dengan volume sebesar $216 \mathrm{~cm}^{3}$ berdasarkan ukuran bahan diperoleh strip bambu ketebalan $1 \mathrm{~mm}$ sebanyak $31,5 \mathrm{~cm}^{3}$ (7 strip) atau sekitar $14,58 \%$, strip bambu ketebalan $1,5 \mathrm{~mm}$ sebanyak $74,25 \mathrm{~cm}^{3}$ (11 strip) atau sekitar $34,375 \%$, dan strip bambu ketebalan $2 \mathrm{~mm}$ sebanyak $117 \mathrm{~cm}^{3}$ (13 strip) atau sekitar 54,17\%.
\end{abstract}

Kata kunci : bambu, bilah, penipis, mesin, pisau, motor

\section{ABSTRACT}

Bamboo is one of non-timber forest products that has been utilized for various purposes. One of its utilizations, as building materials, is in terms of shape and strips. However, with the rapid advancement of gluing technology, bamboo can be used as a raw material for plywood core substitution as veneer. The purpose of this research is to produce a machine strips of bamboo slats with thick uniform size that can be set suit. Before introduced to the stripper machine, bamboo stems must first be cut or thinned into the desired size. The symmetrical bamboo slats are then fed into the thinning machine using a bamboo carrier U-shaped device made of iron that leads to roll clamp. At the last roll, a steel blade is in place to divide and thin the bamboo slats. The upper roll clamp serves to clamp and press the bamboo slats. Rendement the average results of the cleavage 1 (one) sized bamboo rod $8 \mathrm{~mm}$ thick, $1.5 \mathrm{~cm}$ wide and $30 \mathrm{~cm}$ long with a volume of $216 \mathrm{~cm}^{3}$ based on the size of the bamboo strips obtained material thickness of $1 \mathrm{~mm}$ by $31.5 \mathrm{~cm}^{3}$ (7 strips) or about 14, 58\%, bamboo strip thickness of $1.5 \mathrm{~mm}$ by $74.25 \mathrm{~cm}^{3}$ (11 strips) or about 34.375\%, and a thickness of $2 \mathrm{~mm}$ bamboo strips as 117 $\mathrm{cm}^{3}$ (13 strips) or approximately $54.17 \%$.

Keywords: bamboo, strip, thinning, machines, knife, motors

\section{PENDAHULUAN}

Pada saat ini di Indonesia belum ada

komoditi bambu sebagai bahan untuk industri kayu lapis yang mengembangkan mensubtitusi pembuatan kayu lapis. 
Apabila hal ini dikembangkan maka akan dapat mengurangi beban hutan alam yang selama ini dijadikan sumber bahan baku industri pengolahan kayu.

Bambu lapis adalah papan/panel buatan yang terdiri dari susunan bilah bambu sejajar dan melintang (laminated board) atau anyaman bilah bambu (bamboo mat plywood) dengan diikat oleh perekat tertentu, dan jumlah lapisannya harus ganjil. Bambu lapis dibuat dari bambu 10 - $25 \mathrm{~mm}$ lebar dan 0,8 - 5,0 mm tebal. Jika dilem sejajar berbarengan, terbentuk semacam vinir bambu yang dapat disusun dan dilem mirip tripleks atau multipleks.

Untuk menghasilkan tutu/strip dari bilah bambu, umumnya dilakukan secara tradisional, yaitu diiris atau disayat dengan menggunakan pisau potong atau parang. Hal ini tentu saja cukup banyak memakan waktu dan pekerjaan berjalan lambat. Untuk mengatasi hal tersebut maka perlu suatu alat/mesin pembuat strip bambu yang bekerja secara mekanis guna memudahkan dan mempercepat proses pembelahan bilah bambu.

Tujuan penelitian ini adalah merekayasa mesin strip bambu untuk menghasilkan bilah-bilah/strip-strip bambu dengan ukuran tebal seragam yang dapat diatur sesuai keinginan agar proses pembelahan bisa lebih cepat dan mudah.

\section{BAHAN DAN METODE}

Bahan dan peralatan yang diperlukan meliputi: besi pejal/silinder $4,5 \mathrm{~cm}$ dan 9 $\mathrm{cm}$; pully SPA $\Phi 7 \mathrm{~cm}$ dan $15 \mathrm{~cm}$; V-Belt tipe A 35; Pillow Blok Bearing $\Phi 4 \mathrm{~cm}$; Motor Listrik 3 phase 0,75 HP 1790 rpm; Besi siku $50 \mathrm{~mm}$ dan besi U; Roda Gigi $\Phi$ $50 \mathrm{~mm}-70 \mathrm{~mm}$; Gear $\Phi 6.5 \mathrm{~cm}$ dan rantai besi; Pegas $\Phi 2 \mathrm{~mm}$ dan $3 \mathrm{~mm}$; Plat baja 3 $\mathrm{mm}$; Pisau Baja; Tempat pisau; Switch ON/OFF; dan berbagai jenis bambu.

Metoda pelaksanaan dimulai dengan pembuatan gambar/desain alat; pembuatan alat; cara kerja alat; uji coba alat dan analisis alat/mesin. Sebelum ditipiskan, bambu utuh perlu dibelah menjadi beberapa bagian yang lebih kecil. Misal bambu jenis betung yang mempunyai diameter dapat mencapai 20 $\mathrm{cm}$ dengan tebal dinding antara 1 sampai $3 \mathrm{~cm}$. Pada bambu jenis ini pembelahannya sebaiknya dilakukan ketika masih basah, sebab jika telah kering akan lebih sulit dilakukan. Pembelahan dapat dilakukan dengan dua cara yaitu manual atau menggunakan alat bantu.

Teknik pembelahan menggunakan alat bantu pada mesin dapat dilihat pada Gambar 1 berikut.
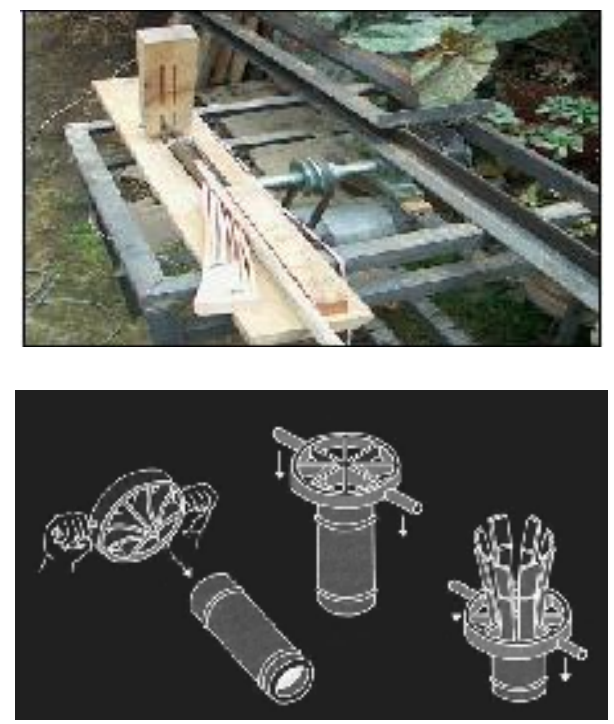

Gambar 1. Teknik pembelahan bambu dengan menggunakan alat bantu.

Prosedur Pembuatan Alat yaitu, membuat gambar dan desain alat; menyiapkan bahan dan peralatan kerja, termasuk menyiapkan mata pisau baja; membuat rangka dan pondasi alat; memasang motor listrik; memasang As Silender dan rangkaian pembawa bambu lainnya; memasang pisau dan penyetelan tempat pisau; evaluasi dan pengerjaan akhir.

Prinsip kerja alat ini berdasarkan sistem mekanis, yaitu menggerakkan 3 (tiga) buah silinder (roller) bagian bawah dengan bantuan gerak dari motor listrik 3 phase $1 \mathrm{Hp}$. Terdapat 3 pasang silender yang berfungsi sebagai penjepit dan pembawa bambu menuju mata pisau. Silinder bagian bawah dirangkai seri dengan rantai dan dihubungkan dengan motor penggerak. Sedangkan silinder 
bagian atas berfungsi untuk menjepit bambu dengan arah putar yang berlawanan dengan silinder bagian bawah. Kekuatan jepit silender atas diatur dengan sistem pegas.

Bahan baku yang berupa bilah bambu dimasukkan pada blok pemasukan yang berfungsi sebagai pengarah dan penyetabil masuknya bilah bambu pada sepasang roller pertama. Bilah bambu tersebut selanjutnya akan terjepit diantara 3 (tiga) pasang roller dan bergerak menuju mata pisau di depannya. Ketebalan irisan diatur dengan penempatan pondasi pisau penipis yang dapat maju-mundur dan naik-turun. Dengan demikian bilah bambu akan dapat teriris dengan ukuran tebal yang sama.

\section{HASIL DAN PEMB AHASAN}

\subsection{Pembuatan Gambar/Desain Alat}

Desain mesin penipis bambu ini berdasarkan fungsi-fungsi yang ada pada komponen mesin. Gambar desainnya sebagai berikut.

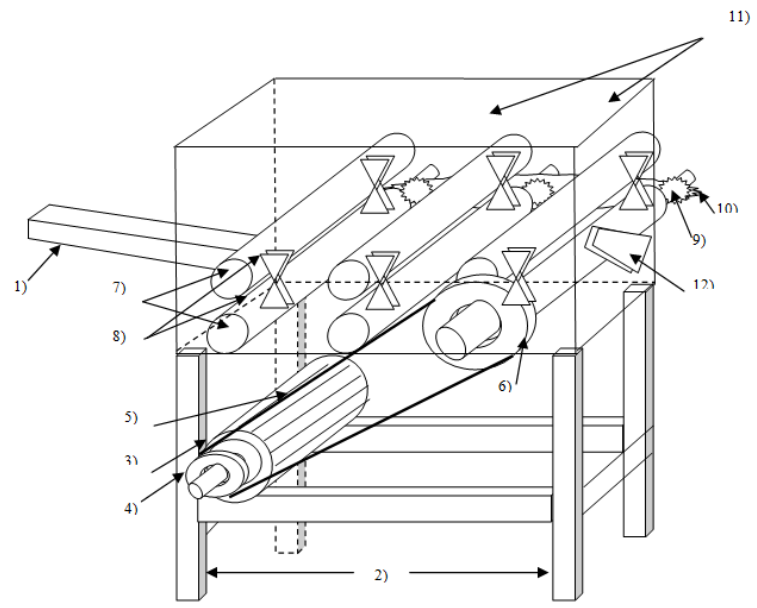

Gambar 2. Desain Mesin Pembuat Strip Bambu.

Keterangan:

1. Tempat masukan benda kerja (bilah bambu).

2. Motor listrik.

3. V-belt.

4. Poros silinder.

5. Roda gigi.

6. Pegas.

7. Pondasi rangka mesin.

8. Pully 2,75 inchi

9. Pully 6 inchi.

10. Bearing.

11. Rantai

12. Mata Pisau dan tempat pisau.

Secara umum proses pembuatan mesin strip bambu digambarkan dengan diagram alur berikut :

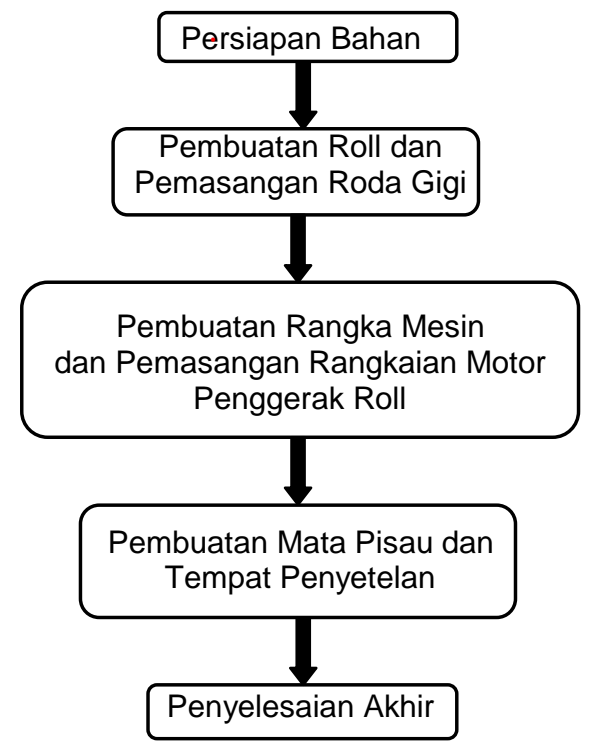

Gambar 3. Alur Pengerjaan Mesin Pembuat Strip Bambu.

\subsection{Cara Kerja Mesin}

Cara kerja mesin ini berdasarkan sistem mekanis, yaitu menggerakkan dua buah silinder (roller) atas dan bawah dengan bantuan gerak dari motor listrik yang telah direducer kecepatannya. Bahan baku yang berupa bilah bambu dimasukkan pada blok pemasukan yang berfungsi sebagai pengarah dan penyetabil masuknya bilah bambu pada kedua roller, bilah bambu tersebut akan terjepit diantara kedua buah roller dan bergerak menuju pisau di depannya. Bilah bambu tersebut akan teriris dengan ukuran tebal yang sama, dan dapat diatur ketebalannya sesuai dengan keinginan.

\subsection{Uji Coba Mesin}

Mesin yang telah dirakit, akan diuji coba ketepatan penepisan bilah bambu dan unjuk kerja secara keseluruhan. Sebelum bambu ditipiskan menggunakan mesin strip (mesin penipis), batang bambu dipotong-potong terlebih dahulu sesuai dengan ukuran yang diinginkan. Bambu dengan ukuran panjang seragam tersebut, kemudian dibelah menjadi beberapa bagian sesuai ukuran lebar yang diinginkan. Bagian kulit terluar, bagian dalam dan kedua sisi kanan \& kiri diratakan agar menjadi bilah bambu yang simetris (misal ukuran plt: $30 \times 2 \times 1 \mathrm{~cm}$ ). Pilihlah 
bagian buku bambu, karena bagian ruas mempunyai sifat yang cukup keras (dapat merusak mata pisau penipis).

Bilah bambu yang simetris dimasukkan ke dalam mesin penipis melalui ujung pembawa bambu dari besi bentuk $U$ yang menuju pada 3 (tiga) pasang roll penjepit dengan tenaga motor listrik. Pada ujung roll terakhir, tedapat mata pisau baja yang berfungsi untuk membelah dan menipiskan bilah bambu. Roll penjepit bagian atas berfungsi sebagai penjepit dan penekan bilah bambu. Mata pisau baja dapat diatur maju-mundur dan naik turun untuk pengaturan tebal sayatan yang diinginkan.

Kecepatan putar roll pembawa berdasarkan kombinasi antara kecepatan motor listri, pully dan roda gigi yang terangkai.

$\begin{array}{lll}\text { N1 motor } & : & 1500 \mathrm{rpm} \\ \text { D1 pully motor } & : & 2,75 \text { inchi } \\ \text { D2 pully roll } & : & 6 \text { inchi } \\ \text { Roda gigi 14 } & : & 4 \text { buah, semua sama } \\ & & \text { (dapat diabaikan) }\end{array}$

Jadi didapat kecepatan putaran pada roll pembawa bambu adalah:

$$
\begin{aligned}
\mathrm{N} \text { roll } & =\frac{\mathrm{D} 1}{\mathrm{D} 2} \times \mathrm{N} 1 \\
& =\frac{2,75}{6} \times 1500 \mathrm{rpm}=0,4853 \times 1500 \mathrm{rpm} \\
& =687,5 \mathrm{rpm}
\end{aligned}
$$

Roll pembawa bambu dirangkai dari 3 (tiga) pasang silinder diameter $9 \mathrm{~mm}$. Bagian roll yang bergerak yang dihubungkan dengan motor listrik adalah bagian roll bawah, sedangkan bagian roll atas hanya berfungsi sebagai penjepit dengan bantuan penempatan pegas diantara roll atas dan bawah. Pada bagian akhir roll penjepit terdapat mata pisau baja dengan dukukan yang dapat diatur majumundur dan atas-bawah. Hal ini dilakukan untuk mengatur ketebalan strip bambu yang diinginkan.

Uji coba dengan benda kerja (bilah bambu) tebal $8 \mathrm{~mm}$, lebar $1,5 \mathrm{~cm}$ dan panjang $30 \mathrm{~cm}$, dengan ketebalan penipisan diatur $1 \mathrm{~mm}, 1,5 \mathrm{~mm}$ dan $2 \mathrm{~mm}$ dengan ulangan masing-maing sebanyak 6 kali diperoleh hasil seperti pada Tabel 4.2, Tabel 4.3 dan Tabel 4.4 .

Dari hasil uji coba pula diperoleh bahwa bilah bambu (ketebalan input benda kerja) yang dapat ditipiskan ketebalan maksimumnya adalah 8,7 mili meter, dan ketebalan minimumnya 3,6 mili meter.

\subsection{Analisis Alat/Mesin}

Mesin penipis yang telah diuji coba dianalisa kelemahan dan kekurangannya agar dapat bekerja secara optimal. Besarnya variasi ketebalan (kurang presisi) dan sedikitnya rendeman dipengaruhi oleh rangkaian roll pembawa yang tidak stabil dan kurang tajamnya mata pisau. 3 (tiga) pasang roll pembawa tidak bekerja dengan baik dalam menghantarkan bilah bambu menuju mata pisau (tidak stabil).

Mesin pembuat strip bambu ini dirancang secara sederhana dan mempunyai 5 (lima) unit utama, yaitu:

1. Motor listrik

2. Roll silinder pembawa

3. Rangkaian roll pembawa berupa pully, V-belt, roda gigi dan rantai.

4. Mata pisau.

5. Rangka mesin.

Daftar komponen mesin pembuat strip bambu dijabarkan dalam Tabel 1 . di bawah ini.

\begin{tabular}{|c|c|c|c|}
\hline No. & Nama Komponen & Jumlah & Satuan \\
\hline 1. & Tiang penyangga besi L & 4 & Buah \\
\hline 2. & Pondasi tiang penyangga & 4 & Buah \\
\hline & $\begin{array}{l}\text { Motor listrik } 3 \text { phase } 380 \text { v } 1500 \\
\text { rpm }\end{array}$ & 1 & Buah \\
\hline 4. & Pondasi motor listrik & 1 & Buah \\
\hline 5. & Switch On/Off motor listrik & 1 & Buah \\
\hline 6. & Kabel listrik NYM $(3 \times 2,5 \mathrm{~mm})$ & 5 & Meter \\
\hline 7. & Pully 2,75 inchi & 1 & Buah \\
\hline 8. & Pully 6 inchi & 1 & Buah \\
\hline & V-belt tipe $A$ & 1 & Buah \\
\hline 10. & Besi letter U & 1 & Meter \\
\hline 11. & $\begin{array}{l}\text { Besi Silender kombinasi } \Phi 45 \mathrm{~mm} \\
\text { dan } \Phi 90 \mathrm{~mm}\end{array}$ & 3 & Buah \\
\hline 12. & Pillow Blok Bearing $45 \mathrm{~mm}$ & 13 & Buah \\
\hline 13. & Roda gigi 14 & 4 & Buah \\
\hline 14. & Pegas $\Phi 3 \mathrm{~mm}$ & 2 & Buah \\
\hline 15. & Pegas $\Phi 4 \mathrm{~mm}$ & 4 & Buah \\
\hline 16. & Mata Pisau Baja dan pondasi & 1 & Buah \\
\hline 17. & Penutup atas & 1 & Buah \\
\hline 18. & Baut dan Mur & 30 & Buah \\
\hline
\end{tabular}

Tabel 1. Daftar Komponen Mesin Pembuat Strip Bambu. 


\subsection{Spesifikasi Mesin}

Spesifikasi mesin pembuat strip bambu adalah sebagai berikut :
1. Daya Motor : 3 HP 380 Volt $1500 \mathrm{rpm}$
2. Kecepatan potong bilah bambu : $687,5 \mathrm{rpm}$
3. Ampere motor : $1,5 \mathrm{~A}$
4. Diameter pully motor : 2,75 “
5. Diameter pully penggerak roll : 6“"
6. Transmisi : V-belt tipe A no.41
7. Diameter poros roll : $45 \mathrm{~mm}$ dan $90 \mathrm{~mm}$
8. Panjang poros : $15 \mathrm{~cm}$
9. Panjang mesin : $79,5 \mathrm{~cm}$
10.Lebar mesin : $44,5 \mathrm{~cm}$
11.Tinggi mesin $: 115 \mathrm{~cm}$
12.Berat mesin : $23 \mathrm{~kg}$

\subsection{Cara Kerja Mesin}

Motor listrik yang terhubung dengan rangkaian pully dan v-belt menggerak-kan poros silinder bawah yang dijepit oleh poros silender atas dengan bantuan pegas. Bilah bambu yang dimasukkan ke dalam 3 (tiga) pasang poros/roll silender dibawa menuju mata pisau yang dapat diatur ketebalan potongan. Jepitan poros/roll silinder atas dapat diatur pula tekanan jepitnya.

Prosedur kerja alat sebagai berikut:

1. Hidupkan motor listrik dengan menekan tombol On pada switch On/Off mesin.

2. Atur dudukan mata pisau agar dekat pada roll silender terakhir.

3. Masukkan bilah bambu melalui alur input mesin.

4. Periksa ketebalan strip bambu yang dihasilkan.

5. Atur kembali dudukan mata pisau agar ketebalan strip bambu yang diinginkan dapat terpenuhi.

6. Jika telah selesai, matikan motor listrik dengan menekan tombol Off pada switch On/Off.

\subsection{Rendemen Hasil dan Akurasi Mesin}

Rendemen penipisan bambu berupa strip yang dihasilkan dari rata-rata 3 contoh bambu utuh berukuran tebal $8 \mathrm{~mm}$, lebar $1,5 \mathrm{~cm}$ dan panjang $30 \mathrm{~cm}$ dengan volume sebesar $216 \mathrm{~cm}^{3}$, yaitu menghasilkan strip bambu ketebalan $1 \mathrm{~mm}$ sebanyak $31,5 \mathrm{~cm}^{3}$ (7 strip) atau sekitar $14,58 \%$, strip bambu ketebalan $1,5 \mathrm{~mm}$ sebanyak $74,25 \mathrm{~cm}^{3}(11$ strip) atau sekitar 34,375\%, dan strip bambu ketebalan $2 \mathrm{~mm}$ sebanyak $117 \mathrm{~cm}^{3}$ (13 strip) atau sekitar 54,17\%.

Waktu rata-rata proses pembelahan menggunakan mesin ini selama $\pm 20,02$ menit. Pembuatan strip bambu menggunakan cara pembelahan manual dengan piasu potong memerlukan waktu selama $\pm 45,24$ menit. Jadi terdapat selisih waktu pengerjaan selama $\pm 25,22$ menit. Dengan kata lain, pembelahan bilah bambu menggunakan mesin ini lebih cepat waktunya dibandingkan dengan pembelahan manual menggunakan pisau potong biasa.

Bahan baku bilah bambu sebanyak 6 bilah dengan ukuran, tebal $8 \mathrm{~mm}$, lebar 1,5 $\mathrm{cm}$ dan panjang $30 \mathrm{~cm}$ dengan volume 216 $\mathrm{cm}^{3}$ dihasilkan strip bambu dengan tebal 1 $\mathrm{mm}$ dan dalam keadaan baik sebesar $7 \mathrm{x}$ $(0.1 \times 1,5 \times 30) \mathrm{cm}=31,5 \mathrm{~cm}^{3}$ (7 strip) atau sekitar $14,58 \%$.

Bahan baku bilah bambu sebanyak 6 bilah dengan ukuran, tebal $8 \mathrm{~mm}$, lebar 1,5 $\mathrm{cm}$ dan panjang $30 \mathrm{~cm}$ dengan volume 216 $\mathrm{cm}^{3}$ dihasilkan strip bambu dengan tebal $1,5 \mathrm{~mm}$ dan dalam keadaan baik sebesar $11 \times(0.15 \times 1,5 \times 30) \mathrm{cm}=74,25 \mathrm{~cm}^{3}(11$ strip) atau sekitar $34,375 \%$.

Bahan baku bilah bambu sebanyak 6 bilah dengan ukuran, tebal $8 \mathrm{~mm}$, lebar 1,5 $\mathrm{cm}$ dan panjang $30 \mathrm{~cm}$ dengan volume 216 $\mathrm{cm}^{3}$ dihasilkan strip bambu dengan tebal 1 $\mathrm{mm}$ dan dalam keadaan baik sebesar $13 \mathrm{x}$ $(0.2 \times 1,5 \times 30) \mathrm{cm}=117 \mathrm{~cm}^{3}$ (13 strip) atau sekitar $54,17 \%$.

Akurasi penipisan masih kurang baik, ketebalan awal, tengah dan akhir strip tidak sama. Selain itu, awal bilah bambu yang mengenai mata pisau terjadi kerusakan akibat tumbukan yang relatif keras.

Bilah bambu yang dapat ditipiskan maksimum dengan tebal 8,7 mili meter, dan minimum setebal 3,6 mili meter. Hal ini disebabkan karena konstruksi poros silender atas tidak bergerak (hanya sebagai penjepit benda kerja). Akibatnya, bilah bambu yang bergoyang ketika masuk mata pisau (tidak stabil). 
Tabel 2. Ketebalan potongan penipisan $1 \mathrm{~mm}$

\begin{tabular}{cccrrrr}
\hline Contoh Uji & $\begin{array}{c}\text { Tebal } \\
\text { Bambu }\end{array}$ & $\begin{array}{c}\text { Penipisan } \\
\text { Strip }\end{array}$ & $\begin{array}{c}\text { Strip Bag. } \\
\text { Awal }\end{array}$ & $\begin{array}{c}\text { Strip Bag. } \\
\text { Tengah }\end{array}$ & $\begin{array}{c}\text { Strip Bag. } \\
\text { Akhir }\end{array}$ & $\begin{array}{c}\text { Tebal Strip } \\
\text { Rata-rata }\end{array}$ \\
\hline 1 & $8 \mathrm{~mm}$ & $1 \mathrm{~mm}$ & $1 \mathrm{~mm}$ & $1,21 \mathrm{~mm}$ & $1,56 \mathrm{~mm}$ & $1,257 \mathrm{~mm}$ \\
2 & $8 \mathrm{~mm}$ & $1 \mathrm{~mm}$ & $1 \mathrm{~mm}$ & $1,13 \mathrm{~mm}$ & $1,37 \mathrm{~mm}$ & $1,167 \mathrm{~mm}$ \\
3 & $8 \mathrm{~mm}$ & $1 \mathrm{~mm}$ & $1,1 \mathrm{~mm}$ & $1,16 \mathrm{~mm}$ & $1,44 \mathrm{~mm}$ & $1,233 \mathrm{~mm}$ \\
4 & $8 \mathrm{~mm}$ & $1 \mathrm{~mm}$ & $1 \mathrm{~mm}$ & $0,93 \mathrm{~mm}$ & $1,27 \mathrm{~mm}$ & $1,067 \mathrm{~mm}$ \\
5 & $8 \mathrm{~mm}$ & $1 \mathrm{~mm}$ & $1 \mathrm{~mm}$ & $1,15 \mathrm{~mm}$ & $0,98 \mathrm{~mm}$ & $1,043 \mathrm{~mm}$ \\
6 & $8 \mathrm{~mm}$ & $1 \mathrm{~mm}$ & $0,97 \mathrm{~mm}$ & $1,16 \mathrm{~mm}$ & $0,98 \mathrm{~mm}$ & $1,037 \mathrm{~mm}$ \\
Rata-rata & & & $1,012 \mathrm{~mm}$ & $1,123 \mathrm{~mm}$ & $1,267 \mathrm{~mm}$ & $1,134 \mathrm{~mm}$ \\
\hline
\end{tabular}

Tabel 3. Ketebalan potongan penipisan $1,5 \mathrm{~mm}$

\begin{tabular}{ccccccc}
\hline Contoh Uji & $\begin{array}{c}\text { Tebal } \\
\text { Bambu }\end{array}$ & $\begin{array}{c}\text { Penipisan } \\
\text { Strip }\end{array}$ & $\begin{array}{c}\text { Strip Bag. } \\
\text { Awal }\end{array}$ & $\begin{array}{c}\text { Strip Bag. } \\
\text { Tengah }\end{array}$ & $\begin{array}{c}\text { Strip Bag. } \\
\text { Akhir }\end{array}$ & $\begin{array}{c}\text { Tebal Strip } \\
\text { Rata-rata }\end{array}$ \\
\hline 1 & $8 \mathrm{~mm}$ & $1,5 \mathrm{~mm}$ & $1,54 \mathrm{~mm}$ & $1,64 \mathrm{~mm}$ & $1,78 \mathrm{~mm}$ & $1,653 \mathrm{~mm}$ \\
2 & $8 \mathrm{~mm}$ & $1,5 \mathrm{~mm}$ & $1,47 \mathrm{~mm}$ & $1,46 \mathrm{~mm}$ & $1,35 \mathrm{~mm}$ & $1,427 \mathrm{~mm}$ \\
3 & $8 \mathrm{~mm}$ & $1,5 \mathrm{~mm}$ & $1,59 \mathrm{~mm}$ & $1,61 \mathrm{~mm}$ & $1,64 \mathrm{~mm}$ & $1,613 \mathrm{~mm}$ \\
4 & $8 \mathrm{~mm}$ & $1,5 \mathrm{~mm}$ & $1,55 \mathrm{~mm}$ & $1,43 \mathrm{~mm}$ & $1,38 \mathrm{~mm}$ & $1,453 \mathrm{~mm}$ \\
5 & $8 \mathrm{~mm}$ & $1,5 \mathrm{~mm}$ & $1,51 \mathrm{~mm}$ & $1,55 \mathrm{~mm}$ & $1,68 \mathrm{~mm}$ & $1,580 \mathrm{~mm}$ \\
6 & $8 \mathrm{~mm}$ & $1,5 \mathrm{~mm}$ & $1,50 \mathrm{~mm}$ & $1,57 \mathrm{~mm}$ & $1,78 \mathrm{~mm}$ & $1,617 \mathrm{~mm}$ \\
\hline Rata-rata & & & $1,527 \mathrm{~mm}$ & $1,543 \mathrm{~mm}$ & $1,602 \mathrm{~mm}$ & $1,557 \mathrm{~mm}$ \\
\hline
\end{tabular}

Tabel 4. Ketebalan potongan penipisan $2 \mathrm{~mm}$

\begin{tabular}{cccrccc}
\hline Contoh Uji & $\begin{array}{c}\text { Tebal } \\
\text { Bambu }\end{array}$ & $\begin{array}{c}\text { Penipisan } \\
\text { Strip }\end{array}$ & $\begin{array}{c}\text { Strip Bag. } \\
\text { Awal }\end{array}$ & $\begin{array}{c}\text { Strip Bag. } \\
\text { Tengah }\end{array}$ & $\begin{array}{c}\text { Strip Bag. } \\
\text { Akhir }\end{array}$ & $\begin{array}{c}\text { Tebal Strip } \\
\text { Rata-rata }\end{array}$ \\
\hline 1 & $8 \mathrm{~mm}$ & $2 \mathrm{~mm}$ & $1,98 \mathrm{~mm}$ & $1,94 \mathrm{~mm}$ & $1,87 \mathrm{~mm}$ & $1,930 \mathrm{~mm}$ \\
2 & $8 \mathrm{~mm}$ & $2 \mathrm{~mm}$ & $2 \mathrm{~mm}$ & $2,11 \mathrm{~mm}$ & $1,95 \mathrm{~mm}$ & $2,020 \mathrm{~mm}$ \\
3 & $8 \mathrm{~mm}$ & $2 \mathrm{~mm}$ & $2,1 \mathrm{~mm}$ & $2,21 \mathrm{~mm}$ & $2,34 \mathrm{~mm}$ & $2,217 \mathrm{~mm}$ \\
4 & $8 \mathrm{~mm}$ & $2 \mathrm{~mm}$ & $2,03 \mathrm{~mm}$ & $2,03 \mathrm{~mm}$ & $2,22 \mathrm{~mm}$ & $2,093 \mathrm{~mm}$ \\
5 & $8 \mathrm{~mm}$ & $2 \mathrm{~mm}$ & $2,02 \mathrm{~mm}$ & $2,09 \mathrm{~mm}$ & $1,98 \mathrm{~mm}$ & $2,030 \mathrm{~mm}$ \\
6 & $8 \mathrm{~mm}$ & $2 \mathrm{~mm}$ & $1,98 \mathrm{~mm}$ & $1,89 \mathrm{~mm}$ & $1,94 \mathrm{~mm}$ & $1,937 \mathrm{~mm}$ \\
\hline Rata-rata & & & $2,018 \mathrm{~mm}$ & $2,045 \mathrm{~mm}$ & $2,050 \mathrm{~mm}$ & $2,038 \mathrm{~mm}$ \\
\hline
\end{tabular}

Setelah dilakukan uji coba, evaluasi dan perbaikan, ternyata diperoleh analisa bahwa mesin Strip kurang bekerja dengan optimal, karena:

1. Daya motor 3 phase 380 Volt $1500 \mathrm{rpm}$ terlalu besar. Kecepatan roll pembawa bilah bambu sebesar $687,5 \mathrm{rpm}$. Sebaiknya cukup dengan motor listrik 1 phase 220 Volt 1500 rpm dengan
2. komposisi pully 2 inchi dan 18 inchi, sehingga kecepatan roll pembawa atau kecepatan pemotongan hanya 166,66 rpm.

3. Poros/roll silinder atas harus bergerak, tidak hanya sebagai penjepit bilah bambu. Rangkaiannya dapat menggunakan roda gigi dengan sistem berpola U. 
4. Mata pisau harus dari baja karbon dan berbentuk tipis agar dapat memotong bilah bambu dengan ringan.

5. Pengaturan dudukan mata pisau agak rumit, karena terdapat 4 sisi baut dan mur yang harus disetel.

6. Pengaturan tekanan roll penjepit pun cukup rumit, karena harus disesuaikan tekanan yang cocok untuk masingmasing 3 (tiga) pasang roll penjepit tersebut. Jika tekanan terlalu kencang, bilah bambu akan lecet dan tersendat jalannya, namun jika terkanan terlalu longgar maka bilah bambu akan meleset (tidak lurus).

7. Poros/roll silinder atas yang tidak langsung bergerak (tanpa terangkai dengan motor listrik) dan adanya pegas diantara kedua rol penjepit atas dan bawah menyebabkan ketidakstabilan (bergoyangnya) bilah bambu yang dibawa. Tabel 2. Ketebalan potongan penipisan $1 \mathrm{~mm}$.

\section{KESIMPULAN}

Konstruksi mesin cukup sederhana, namun relatif sulit pengaturan atau penyetelannya. Ketebalan strip bambu dapat diatur ketebalannya sampai dengan maksimal $1 \mathrm{~mm}$.

Kapasitas produksi strip bambu bervariasi sesuai dengan kecepatan operasional yang dilakukan. Waktu ratarata membuat strip bambu selama $\pm 20,02$ menit dan lebih cepat $\pm 25,22$ menit dibandingkan dengan pembuatan secara manual.

Rendemen strip bambu yang dihasilkan relatif kecil (14,58\% - 54,17\%). Semakin tipis strip bambu yang diinginkan, semakin kecil rendemennya. Akurasi/presisi hasil strip bambu juga relatif rendah ( $7: 48$ strip untuk ketebalan $1 \mathrm{~mm}, 11$ : 48 strip untuk ketebalan $1,5 \mathrm{~mm}$, dan $13: 48$ strip untuk ketebalan $2 \mathrm{~mm}$ ).

\section{DAFTAR PUSTAKA}

1. Edward L. Paul, Victor A. AtiemoObeng, Suzanne M. Kresta, 2004. Handbook of Industrial Mixing: Science and Practice. John Wiley \& Sons, Inc.,
Hoboken, New Jersey, United States of America.

2. Krisdianto, Ginuk Sumarni dan Agus Ismanto, 2005. Sari Hasil Penelitian Bambu. Departemen Kehutanan RI. (http://www.dephut.go.id/index.php?q=id /node/1241 diakses 12 Agustus 2007).

3. Rachman Effendi, 2007. Kajian Sistem dan Kebutuhan Bahan Baku Industri Pengolahan Kayu di Kalimantan Selatan. Info Sosial Ekonomi. 7 (4). Bogor.

4. Ridwanti Batubara, 2002. Pemanfaatan Bambu di Indonesia. Fakultas Pertanian, Program IImu Kehutanan, Universitas Sumatra Utara. (http://library.usu.ac.id/download/fp/huta n-ridwanti4.pdf diakses 25 Mei 2007).

5. SOLIH ROKYANA, 2000. Perhitungan Konstruksi Mesin 2. Bidang Keahlian Teknik Mesin, Amico. Bandung.

6. Sunyoto, Karnowo, S. M. Bondan Respati, 2008. Teknik Mesin Industri Jilid 1 untuk SMK, Direktorat Pembinaan Sekolah Menengah Kejuruan, Direktorat Jenderal Manajemen Pendidikan Dasar dan Menengah, Departemen Pendidikan Nasional, 204 halaman. Jakarta.

7. Solih Rokyana. 2000. Perhitungan Konstruksi Mesin 2. Bidang Keahlian Teknik Mesin, Amico. Bandung.

8. Yanuarianto, 2000. Peningkatan Kinerja Mesin Pemotong Batu Aji. Baristand Indag Banjarbaru. Banjarbaru. 
